EXTENDED REPORT

\title{
Surgical coverage of exposed hydroxyapatite implant with retroauricular myoperiosteal graft
}

\author{
S L Liao, S C S Kao, J H S Tseng, L L-K Lin
}

Br J Ophthalmol 2005;89:92-95. doi: 10.1136/bjo.2003.038778

Background: With the increasing use of hydroxyapatite orbital implants, the complication of exposure has become apparent to oculoplastic surgeons. Many kinds of patch grafts, such as sclera, dermis, and hard palate mucosa, have been used to cover exposed hydroxyapatite implants with inconsistent results. In this study, the authors use a newly developed technique, autogenous retroauricular myoperiosteal graft, and the results are reported.

See end of article for authors' affiliations

.....................

Correspondence to: Shu-Lang Liao,

$M D$, Department of Ophthalmology, National Taiwan University Hospital, 7, Chung-Shan South Road, Taipei, Taiwan; lang89@ha.mc. ntu.edu.tw

Accepted for publication 28 March 2004
Methods: A piece of retroauricular muscle together with its underlying periosteum was carefully harvested. This myoperiosteal graft was patched to the debrided hydroxyapatite exposure area with the periosteal surface facing outward. The margin of periosteal surface was secured with conjunctiva and left uncovered for the surrounding conjunctiva to epithelialise.

Results: Nine eyes with hydroxyapatite exposure more than $3 \mathrm{~mm}$ were managed with autogenous retroauricular myoperiosteal grafts. Seven cases were successfully treated with single graft surgery. The other two cases needed an additional graft surgery, and there was no re-exposure noted thereafter. Five patients received a successful insertion of the motility peg. All nine patients have been fitted with prosthesis with reasonable motility. There were no complication noted during more than 1 year of follow up.

Conclusion: The thick composite nature of the myoperiosteal graft provides a durable and vascularised coverage for exposed hydroxyapatite implants. This technique offers an encouraging alternative for the management of exposed hydroxyapatite implants.
$\mathrm{P}$ orous hydroxyapatite has been used as an orbital implant for socket reconstruction after enucleation and evisceration since 1985. The material was developed by Perry and has becoming increasing popular. ${ }^{1}$

In earlier reports, the orbital hydroxyapatite implant appeared to provide superior cosmesis and motility, with minimal infection and extrusion. ${ }^{2}{ }^{3}$ However, with the increasing use, many reports of implant exposures were noted, giving rates ranging from $1.6 \%$ to $21.6 \%{ }^{1}{ }^{4-7}$ The need to deal with this complication has become obvious to oculoplastic surgeons. ${ }^{5}$ Many patch graft materials, such as banked sclera, ${ }^{8-12}$ dermis fat grafts, ${ }^{5}$ hard plate mucosa, and temporalis fascia and fascia lata ${ }^{13}$ have been proposed with variable results. Poor vascularisation and graft melting were frequently seen in cases where such graft materials were used.

This study reports our experience with nine exposed hydroxyapatite implants, which were handled with the newly developed technique of autogenous retroauricular myoperiosteal grafts.

\section{SUBJECTS AND METHODS \\ Patient selection}

Many small exposures $(<3 \mathrm{~mm})$ can be managed conservatively at first. This involves observation and vaulting of the prosthesis to reduce pressure on the underlying tissue. ${ }^{4}$ The criterion included for this study is patients with exposure of the hydroxyapatite surface of more than $3 \mathrm{~mm}$. From January 1994 to February 2003, nine eyes with hydroxyapatite implant exposure of more than $3 \mathrm{~mm}$ were managed with autogenous retroauricular myoperiosteal grafts (table 1). Among these nine patients, there were one referred patient with failed sclera patch graft (case 3 ) and the other referred patient with failed sclera patch graft and another dermis fat graft (case 9). In addition, one patient with sympathetic ophthalmia was found to have $5 \times 6 \mathrm{~mm}$ exposure as a result of long term steroid use (case 7). The detailed information such as age, sex, procedures, and exposure area are summarised in table 1 .

\section{Surgical technique}

All operations were performed by one oculoplastic surgeon (SLL). This procedure was developed with the technique of graft harvesting in the donor site, but also with a variable extent of drilling debridement in the recepient bed.

\section{Recepient bed preparation}

To prepare a healthy recepient bed, the margin of the fibrotic conjunctiva and Tenon's capsule around the exposed area were carefully lifted up and care was taken to preserve the viable tissue as much as possible (fig $1 \mathrm{~A}, \mathrm{~B}$ ). The implant was drilled or burred down on the area of exposure (fig IC). Generous irrigation and strong suction were repeated to facilitate the washout of necrotic debris in the depth of the sphere. Usually, the exposed implant was mostly avascular, and no spotty bleeding from the implant could be observed after the debridement. Therefore, we count heavily on the irrigation and suction as the key steps in our technique. The drilling debridement was intended to level the margin of the recipient bed smoothly, so as to countersink the graft flush with both the Tenon's capsule and the hydroxyapatite. An antibiotic solution, such as garamycin, was injected into the core of the hydroxyapatite. As a result of these manipulations, the recepient bed was well prepared (fig 1D). The actual area of exposure was calipered to determine the graft size to be harvested.

\section{Myoperiosteal graft harvesting}

A curvilinear skin incision was made at the retroauricular area, about $1 \mathrm{~cm}$ away from the choncamastoid suture. Blunt dissection could be performed easily between the subcutaneous tissue and muscular layer to expose the posterior 


\begin{tabular}{|c|c|c|c|c|c|c|c|c|c|}
\hline $\begin{array}{l}\text { Case } \\
\text { no }\end{array}$ & $\begin{array}{l}\text { Age } \\
\text { (years) }\end{array}$ & Sex & Diagnosis & Procedure & $\begin{array}{l}\text { Apparent } \\
\text { tissue defect }\end{array}$ & $\begin{array}{l}\text { Time to defect } \\
\text { after surgery }\end{array}$ & $\begin{array}{l}\text { Duration of } \\
\text { exposure }\end{array}$ & $\begin{array}{l}\text { Re-exposure } \\
\text { after graft }\end{array}$ & Outcome \\
\hline 1 & 42 & M & $\begin{array}{l}\text { Ocular } \\
\text { melanoma }\end{array}$ & Enucleation $20 \mathrm{~mm}$ & $4 \times 5 \mathrm{~mm}$ & 3 weeks & 3 months & No & $\begin{array}{l}\text { Exposure resolution, } \\
\text { peg inserted }\end{array}$ \\
\hline 2 & 25 & $M$ & $\begin{array}{l}\text { Trauma, } \\
\text { phthisis globe }\end{array}$ & Enucleation $20 \mathrm{~mm}$ & $5 \times 6 \mathrm{~mm}$ & 1 month & 3 weeks & No & $\begin{array}{l}\text { Exposure resolution, } \\
\text { peg inserted }\end{array}$ \\
\hline 3 & 31 & $M$ & $\begin{array}{l}\text { Trauma, } \\
\text { disorganised globe }\end{array}$ & Enucleation $20 \mathrm{~mm}$ & $3 \times 3 \mathrm{~mm}$ & 1 month & 6 months* & No & $\begin{array}{l}\text { Exposure resolution, } \\
\text { peg inserted }\end{array}$ \\
\hline 4 & 3 & $\mathrm{~F}$ & Retinoblastoma & Enucleation $18 \mathrm{~mm}$ & $4 \times 4 \mathrm{~mm}$ & 3 months & 3 months & Yes $1 \times 2 \mathrm{~mm}$ & $\begin{array}{l}\text { Myoperiosteal re- } \\
\text { graft, exposure } \\
\text { resolution }\end{array}$ \\
\hline 5 & 28 & $\mathrm{~F}$ & $\begin{array}{l}\text { Trauma, phthisis } \\
\text { globe }\end{array}$ & Enucleation $20 \mathrm{~mm}$ & $6 \times 15 \mathrm{~mm}$ & 3 months & 2 weeks & Yes $3 \times 2 \mathrm{~mm}$ & $\begin{array}{l}\text { Myoperiosteal re- } \\
\text { graft, exposure } \\
\text { resolution }\end{array}$ \\
\hline 6 & 39 & $\mathrm{~F}$ & Endophthalmitis & Evisceration $20 \mathrm{~mm}$ & $4 \times 8 \mathrm{~mm}$ & 3 weeks & 2 months & No & $\begin{array}{l}\text { Exposure resolution, } \\
\text { peg inserted }\end{array}$ \\
\hline 7 & 33 & $M$ & $\begin{array}{l}\text { Trauma, } \\
\text { disoraanised alobe }\end{array}$ & Evisceration $20 \mathrm{~mm}$ & $5 \times 6 \mathrm{~mm}$ & 6 weeks & 3 months $†$ & No & Exposure resolution \\
\hline 8 & 29 & $\mathrm{~F}$ & $\begin{array}{l}\text { Trauma, } \\
\text { disorganised globe }\end{array}$ & Evisceration $20 \mathrm{~mm}$ & $6 \times 8 \mathrm{~mm}$ & 2 months & 7 weeks & No & $\begin{array}{l}\text { Exposure resolution, } \\
\text { peg inserted }\end{array}$ \\
\hline 9 & 45 & M & $\begin{array}{l}\text { Trauma, } \\
\text { disorganised globe }\end{array}$ & Evisceration $20 \mathrm{~mm}$ & $11 \times 16 \mathrm{~mm}$ & 3 weeks & 5 months $\ddagger$ & No & Exposure resolution \\
\hline
\end{tabular}

*Referred patient with a failed sclera patch graft.

†Sympathetic ophthalmia with long term steroid use.

$\ddagger$ Referred patient with failed sclera patch graft and dermis fat graft.

auricular muscle (fig 2A). The size was calipered and the donor area was marked. A scalpel with a No 10 blade was used to incise through the muscle and periosteum layers vertically down to the bony part. The composite graft was harvested with a periosteum elevator, to free the periosteum from the temporal bone. Since the intact posterior auricular muscle tensed on the temporal bone before harvest, the freed graft shrank and became thicker. The composite components of the graft, periosteum, and muscle are shown in figure 2B. The subcutaneous layer of the donor site was closed with 4-0 Dexon interrupted sutures, and the skin wound with 6-0 Nylon continuous sutures.

\section{Myoperiosteal graft application}

The myoperiosteal graft was applied to the recepient bed, with the periosteum surface outward and the muscle layer facing the recepient bed (fig 2C) The graft should be flush tight both on the bed and along the border. The margin of the periosteum layer was secured to the recepient sclera if available or to the Tenon capsule underlying the exposed conjunvtiva with 5-0 Dexon interrupted sutures (fig 3). The
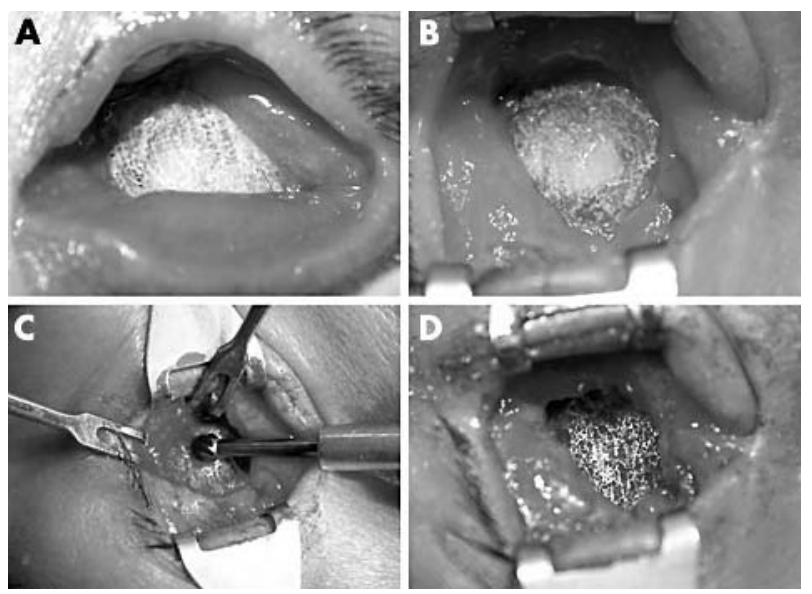

Figure 1 (A) Hydroxyapatite implant exposure measured $11 \times 16 \mathrm{~mm}$. (B) The margin of the fibrotic conjunctiva and Tenon's capsule around the exposed area were carefully lifted up. (C) The implant was burred down on the area of exposure. (D) The recipient bed was well prepared.
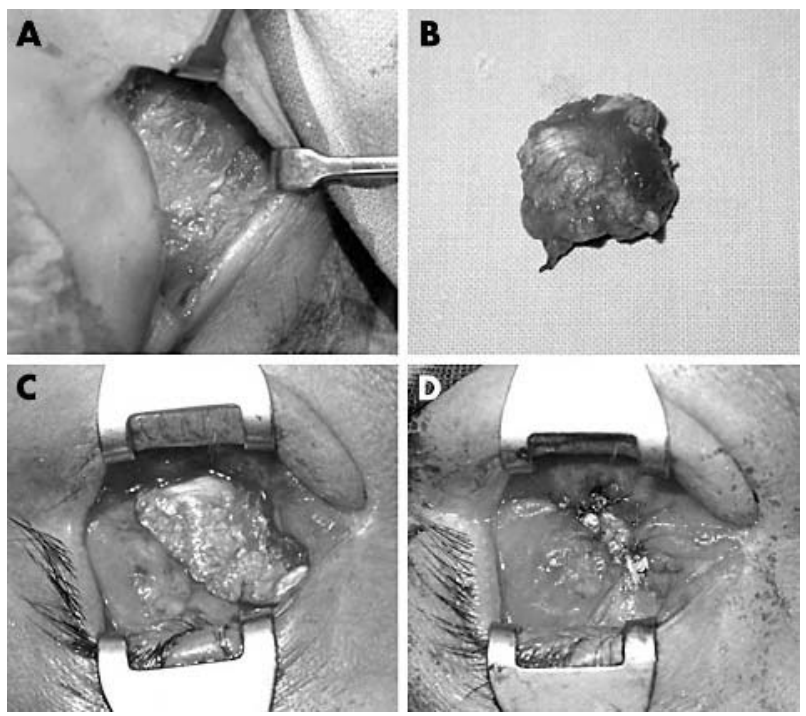

Figure 2 (A) A curvilinear skin incision was made at the retroauricular area and blunt dissection was performed to expose the posterior auricular muscle. (B) The myoperiosteal graft was harvested. (C) The myoperiosteal graft was applied to the recepient bed, with the periosteum surface outward and the muscle layer facing the recipient bed. (D) A conjunctival flap was advanced over the margin of the periosteum and the central area was left bare for epithelialisation.

margin of Tenon's capsule and conjunctival flap was advanced over the margin of the periosteum, and then sutured onto the surface of periosteum with 5-0 Dexon interrupted sutures, as centrally as possible without tension. The central area of the periosteum was left bare for the conjunctival epithelialisation (fig 2D). In this way, the risk of fornix loss could be avoided, especially in those cases of exposure with fibrotic contracture of conjunctival sac. Antibiotic ointment was applied and transparent conformer was inserted.

\section{RESULTS}

Nine eyes with an implant exposure area more than $3 \mathrm{~mm}$ were managed with autogenous retroauricular myoperiosteal 


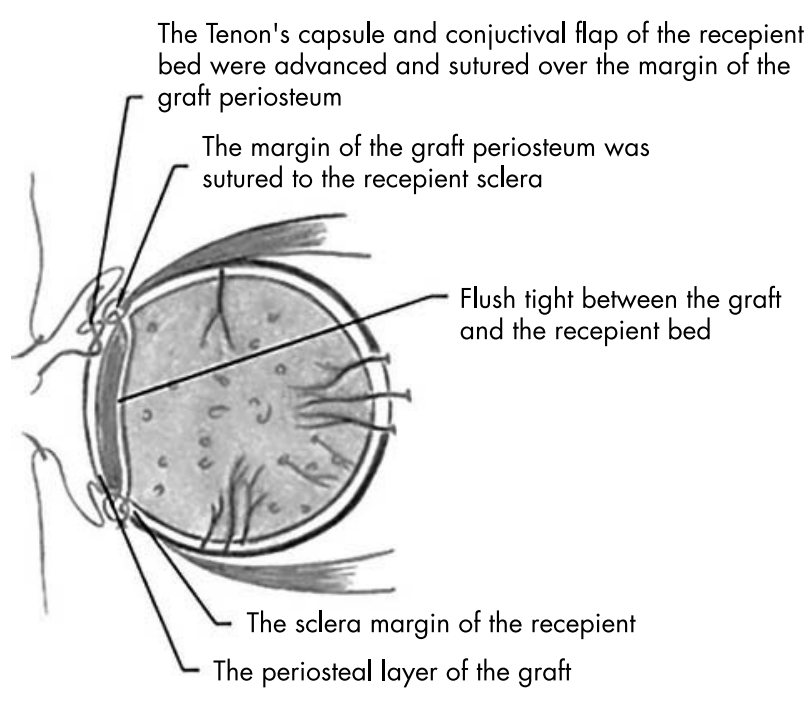

Figure 3 Diagram demonstrates the technique of myoperiosteal graft application.

grafts. The duration between implantation and ocurrence of exposure ranged from 3 weeks to 3 months. The area of exposure measured from $3 \times 3 \mathrm{~mm}^{2}$ to $11 \times 16 \mathrm{~mm}^{2}$. The duration of exposure ranged from 3 weeks to 6 months before treatment with the current method (table 1).

Seven of these nine patients received one myoperiosteal graft only (fig 4), while two patients needed additional surgery (case 4 and 5). In case 5, the myoperiosteal graft had maintained coverage for 3 months, before re-exposure was noted. The area of exposure had shrunk significantly to $3 \times 2 \mathrm{~mm}^{2}$ after myoperiosteal graft compared to the original area of $6 \times 15 \mathrm{~mm}^{2}$. In the other case (case 4), re-exposure was noted 7 weeks after myoperiosteal graft. The area of re-exposure was $1 \times 2 \mathrm{~mm}^{2}$ compared to an initial area of $4 \times 4 \mathrm{~mm}^{2}$ (table 1). Regrafts provided complete resolution.

All patients have been followed up more than 1 year after their last surgery. Five patients received further insertion of a motility peg. No infection or extrusion of the implants were observed during the follow up period. Deep fornices were maintained in all patients except one with mildly contracted fornices (case 6), which had existed before her primary surgery. The cosmesis and motility of prosthesis were good in all patients (fig 5).

\section{DISCUSSION}

Porous hydroxyapatite has been successfully used as an orbital implant in enucleation, evisceration, and as secondary implant since 1985. ${ }^{12}{ }^{14-16}$ The benefits of using this implant is its extensive porous system permitting fibrovascularisation ingrowths, which decrease the risk of implant extrusion and infection. ${ }^{2}{ }^{17}$ In addition, with drilling and peg insertion, this implant can be directly coupled to the prosthesis, allowing a wide range of prosthetic movement, especially fine darting eye movements commonly seen during conversational speech. These movements impart a more lifelike quality to the prosthetic eye. However, with increasing use of hydroxyapatite implant, complications such as tissue breakdown, conjunctival dehiscence, and implant exposure are becoming more apparent to oculoplastic surgeons..$^{4-13}$

Several causes of hydroxyapatite implant exposure had been proposed, including using too large an implant, tension on the wound, excessive inflammation related to hydroxyapatite material itself, ${ }^{78}$ spicules on the hydroxyapatite implant surface, ${ }^{19}$ pressure from the prosthesis to the conjunctival surface, ${ }^{5}$ or inadequate vascularisation of the
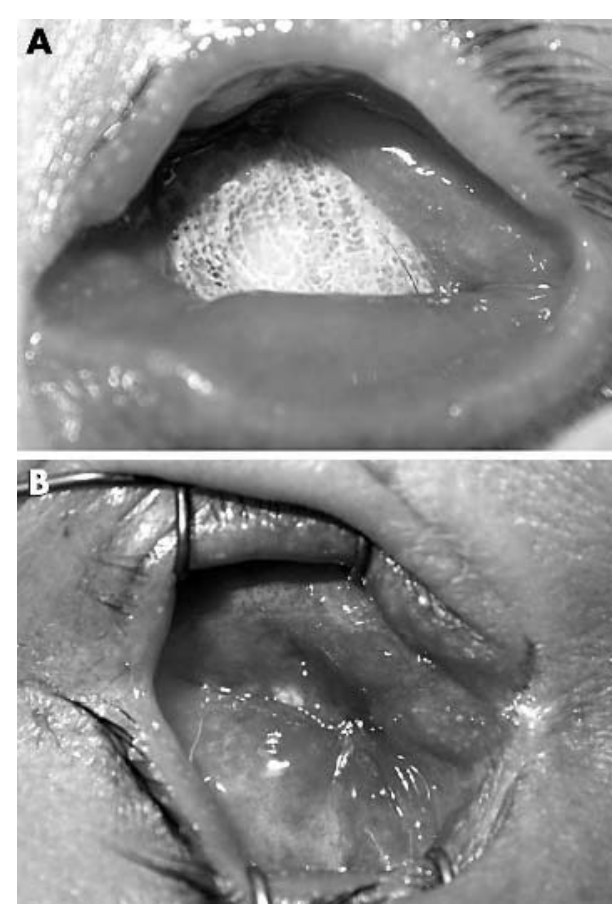

Figure 4 (A) Hydroxyapatite implant exposure measured $11 \times 16 \mathrm{~mm}$. (B) After myoperiosteal graft, exposure was completely resolved.
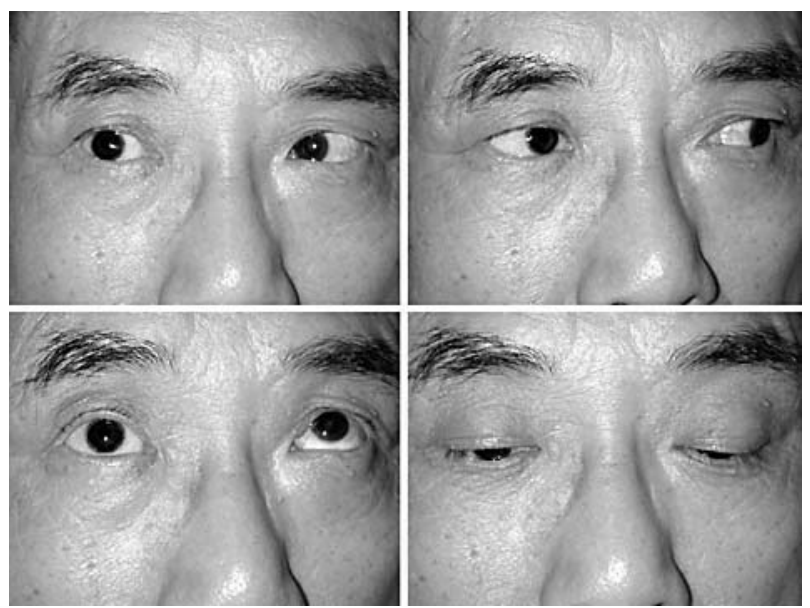

Figure 5 A patient with hydroxyapatite implant exposure received myoperiosteal graft and peg insertion. The movement of the prosthesis is reasonably good.

implant. ${ }^{6}$ They can be prevented by appropriate surgical technique and implant size, covering the implant with the wrapped materials, attempting to accelerate vascularisation and vaulting of the prosthesis.

Small conjunctival defects $(<3 \mathrm{~mm})$ can be managed by observation and vaulting of the prosthesis. ${ }^{12}$ Larger implant exposures $(>3 \mathrm{~mm})$ required a more elaborate approach. Helveston was the first to report the use of human banked sclera patch in $1969 .{ }^{11}$ In their long term fellow up report, there was a 55\% success rate. ${ }^{9}$ The use of banked sclera as a patch has some drawbacks, as it may melt if vascular supply is insufficient. It may potentially contain infectious agents. As a homologous material, it may generate more inflammation than autologous tissue.

Fascia lata or temporalis fascia can be an autologous patch graft for the management of hydroxyapatite exposure. ${ }^{13}$ They 
have a sturdy fibrous tissue thick enough to cover the irregular, speculated surface of implant. In another technique, a dermis fat graft is proposed as a covering for the exposed hydroxyapatite implant. ${ }^{19}$ The technique suggested eliminating a portion of the exposed implant by burring it down or rongeuring it away before placing the dermis fat graft.

In general, a favoured graft for the implant exposure should have both an abundant vascular network for the ready establishment of perfusion, and a tough collagenous layer to resist melting in the early phase of hypoperfusion. In this study, we use the retroauricular myoperiosteal graft as a patch graft. Before placement of the myoperiosteal graft, we eliminated a portion of exposed implant by burring down the non-vascularised coral to establish an abundant vascular bed. We believe the burring procedure is important for the successful management of the hydroxyapatite implant exposure.

In chronic exposure, the porous spaces of hydroxyapatite may harbour infectious pathogens and cause infection or abscess of orbital implants. Jordan et al reported two cases of abscessed hydroxyapatite orbital implants. ${ }^{20}$ They recommended that patients with conjunctival dehiscence postoperatively should be closely observed for infection because organisms may gain access through this portal of entry. Patients with chronic medical diseases or long term steroid use may have a predisposition to infection after implant exposure. In our series, infection of the orbital implant should be considered in the differential diagnosis of hydroxyapatite implant exposure for a patient with sympathetic ophthalmia with long term steroid use (case 7). In the other two cases with regraft (cases 4 and 5), incomplete debridement of infected hydroxyapatite implant might have been partially responsible for the recurrence of implant exposure. Additional debridement of infected implants with re-application of myoperiosteal grafts led to complete resolution. We think that a severe infection or abscess within the exposed implant might require extensive removal or even complete removal of the implant. Smaller or subtotal abscess within the implant is more likely treatable utilising the debridement, irrigation, and reconstruction of the anterior surface with autogenous grafts. Without complete debridement, the fibrovascular ingrowth would be hindered by chronic infection in these dead spaces, with graft sloughing as a result.

Several advantages have been achieved by this technique. Some of the abrasive spicules are eliminated, as well as some of the non-vascularised coral, and burring down the implant creates sufficient space for the placement of the myoperiosteal graft and the proper adjustment of the prosthetic eye. In addition, retroauricular myoperiosteal graft is a sturdy fibrous tissue accompanying the additional muscular layer. The sturdy periosteal surface, which is more durable for melting, should be faced outward; the muscular layer placed inward provides a better cushion for the underlying spiculated surface of the implant, as well as having a little volume effect. Care must be taken to place the myoperiosteal graft flush tight on the recipient bed and the margin of the graft should be secured to the recepient sclera if available or to the Tenon capsule underlying the exposed conjunctiva. In cases 4 and 5, the first graft was not flush tight on the recipient bed. This failure in technique might have been partially responsible for the central melting of the first graft.
In conclusion, retroauricular myoperiosteal graft as a patch graft has several advantages. The procedure is easy to do and may be performed in the same surgical field. As it is an autologous graft, there will be less immunological reactionthat is, it is more resistant to melt. There is no risk of disease transmission. It is a sturdy fibrous tissue accompanying a muscular layer, which can serve as a better cushion by providing an additional muscle layer, as well as providing a layer of periosteum tougher than other grafts such as donor sclera or dermis fat. Because of its accessibility and low donor site morbidity, the retroauricular myoperiosteal graft can be offered as one of the options for robust autogenous tissue in reconstructing the ocular surface following exposed orbital implant.

\section{Authors' affiliations}

S L Liao, J H S Tseng, L L-K Lin, Department of Ophthalmology, National Taiwan University Hospital, Taipei, Taiwan

S C S Kao, Department of Ophthalmology, Hsin Chu Provincial Hospital, Taipei, Taiwan

All authors have no financial interest in the materials described in this paper

This paper had been presented in the 21 st annual meeting of European Society of Ophthalmic Plastic and Reconstructive Surgery in Gothenburg, Sweden, 2003.

\section{REFERENCES}

1 Perry AC. Integrated orbital implants. Adv Ophthalmic Plast Reconstr Surg 1990;8:75-81.

2 Dutton JJ. Coralline hydroxyapatite as an ocular implant. Ophthalmology 1991;98:370-7.

3 Shields CL, Shields JA, De Potter P. Hydroxyapatite orbital implant after enucleation. Experience with 100 consecutive cases. Arch Ophthalmol 1992;110:333-8.

4 Remulla HD, Rubin PAD, Shore JW, et al. Complications of porous spherical orbital implants. Ophthalmology 1995;102:586-93.

5 Buettner H, Bartley GB. Tissue breakdown and exposure associated with orbital hydroxyapatite implants. Am J Ophthalmol 1992;113:669-73.

6 Shields CL, Shields JA, De Potter P, et al. Problems with the hydroxyapatite orbital implant: experience with 250 consecutive cases. Br J Ophthalmol 1994;78:702-6.

7 Nunery WR, Heinz GW, Bonnin JW. Exposure of hydroxyapatite spheres in the anophthalmic socket: histopathologic correlation and comparison with silicone implants. Ophthal Plast Reconstr Surg 1993;9:96-104.

8 Goldberg MF. A simplified scleral graft technique for covering an exposed orbital implant. Ophthalmic Surg 1988;19:206-11.

9 Fountain JA, Helveston EM. A long-term follow-up study of scleral grafting for exposed or extruded orbital implants. Am J Ophthalmol 1982;93:52-6.

10 Zolli C, Shannon GM. Experience with donor sclera for extruding orbital implants. Ophthalmic Surg 1977;8:63-70.

11 Helveston EM. Human bank scleral patch for repair of exposed or extruded orbital implants. Arch Ophthalmol 1969:82:83-6.

12 Goldberg RA, Holds JB, Ebrahimpour J. Exposed hydroxyapatite orbital implants, report of six cases. Ophthalmology 1992;99:831-6.

13 Pelletier CR, Jordan DR, Gilberg SM. Use of temporalis fascia for exposed hydroxyapatite orbital implants. Ophthal Plast Reconstr Surg 1998;14:198-203.

14 Hornblass A, Biesman BS, Eviatar JA. Current techniques of enucleation: a survey of 5,439 intraorbital implants and a review of the literature. Ophthal Plast Reconstr Surg 1995;11:77-88.

15 De Potter P, Shields CL, Shields JA, et al. Use of the hydroxyapatite ocular implant in the pediatric population. Arch Ophthalmol 1994;112:208-12.

16 Massy GG, Holds JB. Coralline hydroxyapatite spheres secondary orbital implants in anophthalmos. Ophthalmology 1995;102:161-6.

17 Shields CL, Shields JA, Eagle RC Jr, et al. Histopathologic evidence of fibrovascular ingrowth four weeks after placement of the hydroxyapatite orbital implant. Am J Ophthalmol 1991;111:363-6.

18 Rosner M, Edward DP, Tso MOM. Foreign-body giant-cell reaction to the hydroxyapatite orbital implant. Arch Ophthalmol 1992;110:173-4.

9 Kim TD, Goldberg RA, Shorr N, et al. Management of exposed hydroxyapatite orbital implants. Ophthalmology 1994;101:1709-15.

20 Jordan DR, Brownstein S, Jolly SS. Abscessed hydroxyapatite orbital implants - a report of two cases. Ophthalmology 1996;103:1784-7. 